\title{
Modification of substandard EPDM with amorphous thermoplastic polyesters (PETG and PEF): microstructure and physical properties
}

\author{
Sandra Paszkiewicz", Izabela Irska, Elżbieta Piesowicz \\ West Pomeranian University of Technology, Institute of Material Science and Engineering, Piastow 19, 70-310 Szczecin, \\ Poland \\ "Corresponding author: e-mail: spaszkiewicz@zut.edu.pl
}

\begin{abstract}
The phase morphology, thermal behavior and mechanical properties of two series of polymer blends based on ethylene/propylene/diene rubber (EPDM) and amorphous homologues of poly(ethylene terephthalate), i.e. glycol modified poly(ethylene terephthalate) (PETG) and poly(ethylene furanoate) (PEF), were investigated. The morphology of the blends shows a two phase structure in which the minor phase (amorphous polyester) is dispersed as domains in the major (EPDM) continuous matrix phase. Differential calorimetry studies confirmed that both systems were immiscible and exhibits two glass transitions. The melting peak area of EPDM in the blends decreased as the amount of the other component increased. The values of stress at strain of $100 \%$ were improved upon the increasing content of PETG in EPDM system, while only slight decrease of this value was observed. Moreover, the strong improvement of hardness and thermo-oxidative stability along with an increasing content of amorphous polyester phase was reported.
\end{abstract}

Keywords: polymer blends; substandard EPDM; PETG; PEF; phase morphology; mechanical properties; thermal stability.

\section{INTRODUCTION}

Ethylene/propylene/diene rubber (EPDM) exhibits excellent heat, ozone, and aging resistance due to its highly saturated chemical structure ${ }^{1}$. Moreover, one can find EPDM as a material resistant to a cold and moisture permanent deformation and impact ${ }^{2}$. One knows that by incorporating saturated EPDM rubber into diene rubbers, such as natural rubber (NR) and butadiene rubber (BR), one can achieve new functional material, which can replace conventional antiozonants, such as $\mathrm{N}$-1,3-dimethylbutyl,-N'-phenyl-para-phenylenediamine $(6 \mathrm{PPD})^{3}$. However, in general vulcanizates of the EPDM/ diene rubber possess poor mechanical properties ${ }^{1}$. Mixing of rubbers with resins and thermoplastics may result in obtaining new materials with different properties in comparison to the starting materials along with an extended range of utilization ${ }^{4}$. Using diverse polymers, one can varied the characteristics of such blends between large limits, thus obtaining new functional materials with balanced properties that cannot be obtained by single polymer ${ }^{2}{ }^{4}$. For many years, such polymer blends have been received by traditional technology used in rubber processing and their properties are well-known ${ }^{5,6}$. By mixing rubbers with thermoplastics under specific conditions one can obtain materials with elastoplastic behaviour: at high temperature they can be processed in the molten state and, after cooling, in the temperature range of usage, they behave as elastomers ${ }^{7}$. Nowadays, such materials are produced and applied at a commercial scale starting from non-polar elastomers and non-polar plastomers, or from polar elastomers and polar plastomers, or from pairs of dissimilar polarity ${ }^{4}$. In general, if the blend contains a relatively large amount of rubbery phase, the blend will be soft and have at least some of the properties of an elastomer, whereas if it contains a relatively large portion of the hard plastic, it can be used as an impact resistant plastic. In these types of blends the required properties can be easily obtained by the careful selection of the component polymers (rubber and plastic) and their blend ratios ${ }^{\mathbf{8}, 9}$. However, most of the rubber/thermoplastic blends are immiscible and incompatible. Generally, the physical, mechanical and rheological properties of immiscible polymer blends depend not only on the constituent polymers but also on the morphologies of the blends ${ }^{\mathbf{1 0}, 11}$. Due to the deformable nature of the minor phase in immiscible polymer blends a wide range of morphologies (size shape and distribution of the dispersed phase) can be obtained during melt processing. Therefore many studies on the morphology of the blends have been performed.

Thermoplastic polyesters, such as poly(ethylene terephthalate) (PET) and poly(butylene terephthalate) (PBT), and more recently glycol modified poly(ethylene terephthalate) (PETG) and poly(ethylene furanoate) (PEF) have been widely used as engineering thermoplastics for packaging, electronics, and other applications ${ }^{12}$. PETG, unlike PET, is an amorphous thermoplastic polyester that exhibits a glass transition temperature $\left(\mathrm{T}_{\mathrm{g}}\right)$ of about $80^{\circ} \mathrm{C}^{13-16}$ and on account of its transparency and clarity, can be applied in medical, pharmaceutical, and cosmetic packaging. In turn, PEF is one of the most promising polyesters derived from 2,5-furandicarboxylic acid (FDCA) ${ }^{17}$, due to its higher $\left(\mathrm{T}_{\mathrm{g}}\right)$, better mechanical properties and surprisingly good barrier properties (reduced permeability toward carbon dioxide $\left(\mathrm{CO}_{2}\right)$ and oxygen $\left(\mathrm{O}_{2}\right)$ ) in comparison to PET. This fact along with that FDCA is a renewable feedstock, makes PEF the most attractive substitute for PET, especially when used as packaging materials ${ }^{18}$. Based on structural considerations, PET and its homologues like PETG and PEF, are capable of specific interactions (e.g. H-bonding), but also, chemical reactions with a variety of other polar polymers. Ester groups, terminal carbonyl and hydroxyl groups, that have been inherently present or formed by thermal decomposition, may participate in interchange reactions $^{19,20}$, esterification ${ }^{21}$, amidation, etc. A general approach to impact-modification of condensation polymers like polyester involves incorporation of a reactive functional moiety into the elastomer ${ }^{12,22-24}$. 
Few studies have been carried out considering the effect of the addition of thermoplastic polymers on the properties of EPDM, including EPDM/PET ${ }^{\mathbf{1 2}}$, EPDM/ poly(trimethylene terephthalate) $(\mathrm{PTT})^{\mathbf{2 5}}, \mathrm{EPDM}^{\mathrm{PBBT}}{ }^{\mathbf{2 6}}$ etc. However, there is no study on the effect of amorphous thermoplastic polyesters, like PETG and/or PEF on the EPDM. Moreover, high processing temperatures of semicrystalline thermoplastic polyesters (above $240^{\circ} \mathrm{C}$ ) might affect the properties of EPDM, which normally is processed at $150-180^{\circ} \mathrm{C}^{27,28}$. Therefore, the main objective of this study is to analyze, for the first time, the influence of the thermoplastic amorphous polyesters (PETG and PEF) on the phase morphology, thermal stability and mechanical properties of EPDM blends. Moreover, it is noteworthy, that the EPDM/PETG and EPDM/PEF blends were prepared at the temperature of $150^{\circ} \mathrm{C}$, which prevents degradation of EPDM during processing.

\section{MATERIAL AND METHODS}

\section{Material}

Substandard EPDM was used in this study, which properties are similar to Keltan $® 4869$ (ethylene content of 64 wt. $\%$, ENB content 8.7 wt.\%, Arlanxeo, Netherlands B.V.) having Mooney viscosity of $48 \mathrm{ML}(1+4)$ at $\left.125^{\circ} \mathrm{C}\right)$.

Both amorphous polyesters, i.e. PETG and PEF were synthesised following the same procedure as already published $\mathrm{in}^{\mathbf{2 9}, \mathbf{3 0}}$. For PETG synthesis the following chemicals were used: dimethyl tereftalate (DMT) (Sigma Aldrich); ethane-1,2-diol (ED) (Sigma - Aldrich), 1,4-cycloheksanedimethanol (CHDM) (Sigma - Aldrich), zinc acetate $\mathrm{Zn}\left(\mathrm{CH}_{3} \mathrm{COO}\right)_{2}$ (ester exchange catalyst) (Sigma - Aldrich); germanium dioxide $\left(\mathrm{GeO}_{2}\right)$ (polycondensation catalyst) (PPM Pure Metals $\mathrm{GmbH}$ ); thermal stabilizer Irganox 1010 (Ciba - Geigy, Switzerland). In turn, for PEF synthesis one used: dimethyl furan 2,5-dicarboxylate (DMF) (Sarchem Laboratories, Inc., Farmingdale, NJ, USA), ethane-1,2-diol (ED) (Sigma - Aldrich), tetrabutyl orthotitanate $\left(\mathrm{Ti}(\mathrm{OBu})_{4}\right)$ (ester exchange and polycondensation catalyst) (Fluka); thermal stabilizer Irganox 1010 (Ciba - Geigy, Switzerland). The polymerization od PETG and PEF was performed in a $1 \mathrm{dm}^{3}$ high pressure reactor (Autoclave Engineers Pennsylvania, USA) in two stages: transesterification under a constant flow of nitrogen in temperature range of $165-190^{\circ} \mathrm{C}$, in the presence of catalyst for about two hour. When the amount of by-product of this stage (methanol) was at about $90 \%$ of the stoichiometric calculated value, the second stage began. One has added the thermal stabilizer and second portion of catalyst along with the slow increase of the temperature up to $240^{\circ} \mathrm{C}$ and decrease of the pressure. At this stage, the stirring torque change was monitored in order to estimate the melt viscosity of the product. Both syntheses were finished when viscosity of the melt reached the same established value at $240^{\circ} \mathrm{C}$. The molten polyesters were extruded from the reactor into water bath, then granulated and dried before the manufacturing process. The amorphous polyesters, i.e. PEF and PETG used in this study exhibited intrinsic viscosity values of $0.466 \mathrm{dl} / \mathrm{g}$ and $0.625 \mathrm{dl} / \mathrm{g}$, respectively.

\section{Manufacturing process of specimens}

EPDM, PETG and PEF were dried in a vacuum oven at $60^{\circ} \mathrm{C}$ for about $24 \mathrm{~h}$. Two series of polymer blends were prepared with the content of EPDM of 90, 80 and $70 \mathrm{wt} . \%$. After drying the appropriate amount of materials were fed into a Brabender (Germany) DSE25 intermeshing, co-rotating twin-screw extruder with a length/ diameter ratio of 30 . The mixing processes have been carried out at a melt temperature of $150^{\circ} \mathrm{C}$ and the extruder screw speed was set at $60 \mathrm{rpm}$. Then the samples were pressed to the form of square with the dimension of $100 \mathrm{~mm} \times 100 \mathrm{~mm} \times 1.0 \mathrm{~mm}$ at the temperature of $170^{\circ} \mathrm{C}$ and the pressure of 5 bar. Subsequently, the specimens for tensile testes were prepared according to the standard test methods ASTM D638-type V.

\section{Characterization methods}

One can calculate the theoretical solubility parameters for polymers compositions/blends. There are several methods that allow to estimate the solubility parameter $(\delta)$, proposed by number of investigators ${ }^{31}$. The Hoy solubility parameter method is one of the simplest way to evaluate whether one material is miscible or soluble with/in another organic material (solvent, polymer, etc.). This method is mostly applied for structural features like: cis, trans (around double bonds), ortho-, meta-, para- substitution (aromatics), branching (conjugation of double bonds, and rings) ${ }^{\mathbf{3 2}}$. Moreover, the prediction of the solubility parameter is based on three different contributions: a solubility parameter due to dispersion forces $\left(\delta_{d}\right)$ : all non-polar contributions, a polar contribution $\left(\delta_{\mathrm{p}}\right)$ due to dipole forces and hydrogen bond contribution $\left(\delta_{h}\right)$ : only present when the molecule can form hydrogen bonds or due to donor-acceptor interactions $^{33}$. The Hoy's system contains four additive molar functions, a number of auxiliary equations and the final expressions for $\delta_{\text {tot }}$ and its components of $\delta_{\text {tot }}$. Each of these can be regarded as a vector in three-dimensional space, so the total solubility parameter $\delta_{\text {tot }}$ is defined by equation $(1)^{31}$ :

$\delta_{\text {tot }}^{2}=\delta_{d}^{2}+\delta_{p}^{2}+\delta_{h}^{2}$

The full equation that determines the solubility of amorphous polymers $\left(\mathrm{P}_{\mathrm{i}, \mathrm{j}}\right)^{\mathbf{3 1}}$ :

$$
\begin{aligned}
& \Delta \delta=\left[\left(\delta_{d, P i}-\delta_{d, P j}\right)^{2}+\left[\left(\delta_{p, P i}-\delta_{p, P j}\right)^{2}+\right.\right. \\
& +\left[\left(\delta_{h, P i}-\delta_{h, P j}\right)^{2}\right]^{1 / 2}
\end{aligned}
$$

Where, $\Delta \delta$ is difference in the solubility parameters of polymer pairs, and $\delta_{\mathrm{d}}, \delta_{\mathrm{p}}$ and $\delta_{\mathrm{h}}$ are resulting from dispersion forces, polar interaction and hydrogen bonding. The smaller difference in solubility of block pairs $\Delta \delta \leq 5 \mathrm{MPa}^{1 / 2}$ the more soluble they are ${ }^{31}$.

In order to compare the morphology of each blend, the cryogenically fractured surfaces were investigated with Scanning Electron Microscopy using FE-SEM Hitachi SU-70 microscope. Samples were cryofractured in liquid nitrogen and then coated with palladium - gold alloy thin film using thermal evaporation PVD method to provide electric conductivity. SEM analyses were performed at accelerating voltage of $5 \mathrm{kV}$ and secondary electron images were acquired. 
Thermal analysis was carried out using a differential scanning calorimeter (Q1000, TA Instrument, USA) to study the influence of the addition of amorphous polyesters on the thermal behavior of EPDM/PETG and EPDM/PEF blends. Samples of approximately $9 \mathrm{mg}$ were placed in an aluminum pan. The following program was used: cooling to $-90^{\circ} \mathrm{C}$, then heating up to $220^{\circ} \mathrm{C}$, cooling to $-90^{\circ} \mathrm{C}$ and again heating to $220^{\circ} \mathrm{C}$. The heating and cooling processes were carried out at $10^{\circ} \mathrm{C} / \mathrm{min}$. All measurements were performed under the nitrogen atmosphere.

The tensile properties of the prepared EPDM/PETG and EPDM/PEF polymer blends were measured using Autograph AG-X plus (Shimadzu) tensile testing machine equipped with a $1 \mathrm{kN}$ Shimadzu load cell, an contact optical long travel extensometer and the TRAPEZIUM $\mathrm{X}$ computer software, operated at a constant crosshead speed of $25 \mathrm{~mm} / \mathrm{min}$. Measurements were performed at room temperature with the grip distance of $20 \mathrm{~mm}$. According to DIN 53455 standard, stress at 100\% strain, yield stress and strain, stress and elongation at break of the polymer blends were determined. Five measurements were conducted for each sample, and the results were averaged to obtain a mean value. Moreover, for the prepared two series of polymer blends, hardness measurements were performed on a Shore A apparatus (Karl Frank GmbH, Type 104, Germany) according to a standard DIN 53505 and ISO 868 and the density was measured at $23^{\circ} \mathrm{C}$ on the hydrostatic balance (Radwag WPE 600C, Poland), calibrated for standards with known density.

The thermo-oxidative analysis of the prepared EPDM/ PETG and EPDM/PEF blends were evaluated by thermogravimetry (TGA 92-16.18 Setaram) using the system measuring simultaneously TG-DSC. Measurements were carried out in an oxidizing atmosphere i.e. dry, synthetic air $\left(\mathrm{N}_{2}: \mathrm{O}_{2}=80: 20 \mathrm{vol} . \%\right)$. The study was conducted at a heating rate of $10^{\circ} \mathrm{C} / \mathrm{min}$ in the temperature range of $20-700^{\circ} \mathrm{C}$. Measurements were conducted in accordance with the PN-EN ISO 11358:2004 standard.

\section{RESULTS AND DISCUSSION}

\section{Solubility assessment}

One can assume that, multiphase polymer blends may exhibit good functional properties if they are compatible/ miscible. The molecular structures of the EPDM, PEF and PETG are shown in Figs. 1.a, b and c respectively. These materials, depending on the temperature, may a)

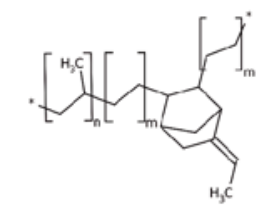

c)

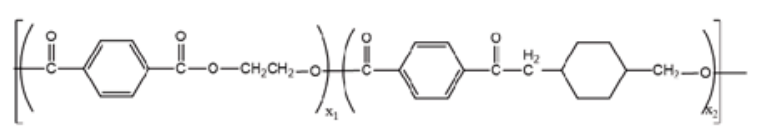

Figure 1. Molecular structures of: a) EPDM, b) PEF, and c) PETG (where $\mathrm{x}_{1}=70 \mathrm{~mol} . \%$ and $\mathrm{x}_{2}=30 \mathrm{~mol} . \%$ ) exhibit the phenomenon of phase solubility and the phase separation, which is due to the large differences between the phase transition temperatures. The characteristic performance of polymer blends is that in the cooled state they form a multiphase structure resulting from micro and nanophase separation, characterized by thermodynamic immiscibility ${ }^{34,35}$. It is possible to calculate the theoretical solubility parameters for polymers compositions. The total solubility parameters and its components were calculated by using Hoy's method Table 1 .

Table 1. Solubility parameters of the EPDM/PETG and EPDM/ PEF blends calculated by using Hoy's method

\begin{tabular}{|l|c|c|c|}
\hline Solubility parameters & $\begin{array}{c}\text { EPDM } \\
{\left[\mathrm{MPa}^{-1}\right]}\end{array}$ & $\begin{array}{c}\mathrm{PETG} \\
{\left[\mathrm{MPa}^{-1}\right]}\end{array}$ & $\begin{array}{c}\mathrm{PEF} \\
{\left[\mathrm{MPa}^{-1}\right]}\end{array}$ \\
\hline$\delta_{\text {tot. }}$ & 19.76 & 33.87 & 31.30 \\
\hline$\delta_{\mathrm{p}}$ & 2.32 & 13.88 & 16.95 \\
\hline$\delta_{\mathrm{h}}$ & 5.71 & 23.38 & 20.75 \\
\hline$\delta_{\mathrm{d}}$ & 18.78 & 20.20 & 16.19 \\
\hline \multicolumn{2}{|c|}{$\Delta \delta_{\text {EPDM-PETG/PEF }}$} & 10.09 & 21.14 \\
\hline
\end{tabular}

$\delta_{\text {tot. }}$ - total solubility parameter, $\delta_{p}-$ a polar contribution due to dipole forces, $\delta_{h}-$ hydrogen bond contribution, $\delta_{d}-$ solubility parameter due to dispersion forces

According to the Hoy's method calculations the obtained polymer blends exhibit higher values of $\Delta \delta$ parameter than parameter appointed for completely miscible materials. This proves that both polymer blends, i.e. EPDM/ PETG and EPDM/PEF are immiscible and exhibit phase separation. Based on the calculations one can deduce that in the cooled state the blends form a heterogeneous structure with two separate phases.

\section{Morphology of EPDM/PETG and EPDM/PEF blends}

Phase morphology of heterogeneous blends plays critical role in determining their final properties. Several important studies ${ }^{\mathbf{3 6}-\mathbf{4 0}}$ give deep insight into the phase morphology of polymer blends These studies predicted that the final morphology is determined by blend ratio, melt viscosity, processing parameters, presence of other ingredients, etc. ${ }^{41}$. The micrographs of cryogenically fractured surfaces of EPDM/PETG and EPDM/PEF blends are displayed in Fig. 2. In Fig. 2 A1-A3 one can observe the dispersed PETG phase within EPDM matrix. However, along with an increase of PETG content (from 10 to $30 \%$ ) the degree of homogeneity of the system decreases, especially when one compares Fig 2 A1 (10\% of PETG) with Fig. 2. A3 (30\% of PETG). This emphasizes on low interfacial adhesion. In turn, EPDM/ PEF blends exhibit even less uniform morphology (Fig. 2 B1-B3). Only in the case of EPDM/PEF 90/10 one can observe dispersed PEF phase in EPDM matrix (Fig. 2 B1). In other cases (Figs. 2 B2 and B3) EPDM/PEF blends revealed worse miscibility of EPDM and PETG phases. The size of PEF phase increased in EPDM/PEF 80/20 and even further increased in EPDM/PEF 70/30. The increase of the size of PETG and PEF phases within EPDM along with their increasing content might result from the coalescence phenomenon. The coalescence, the recombination of particles, is known to take place during the mixing process ${ }^{\mathbf{4 2}}$. These observation are in the agreement with the the Hoy's method calculations made for both systems. The PETG-within-EPDM structure will be 

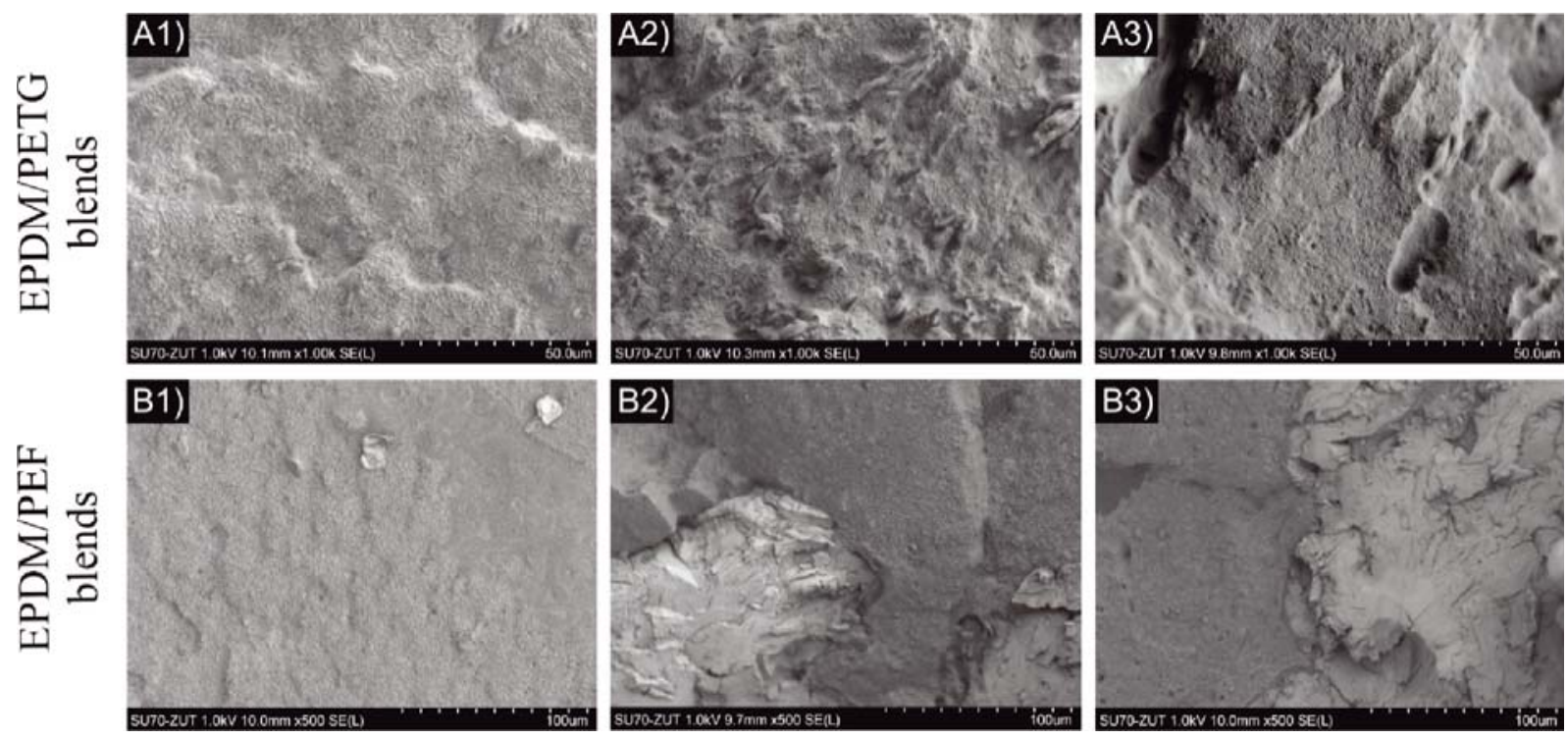

Figure 2. SEM images of two series of EPDM/PETG (A1-A3) and EPDM/PEF blends (B1-B3)

thermodynamically favourable over PEF-within-EPDM structure, since $\Delta \delta_{\text {EPDM/PETG }}<\Delta \delta_{\text {EPDM/PEF }}$

Figure 3 shows DSC thermograms recorded from the $2^{\text {nd }}$ heating of substandard EPDM and its blends of EPDM/ PETG (Fig. 3a) and EPDM/PEF (Fig. 3b). During $2^{\text {nd }}$ heating substandard EPDM exhibits glass transition at about $-57^{\circ} \mathrm{C}$, which is immediately followed by the melting of ethylene component at $\sim 12^{\circ} \mathrm{C}$. This means that
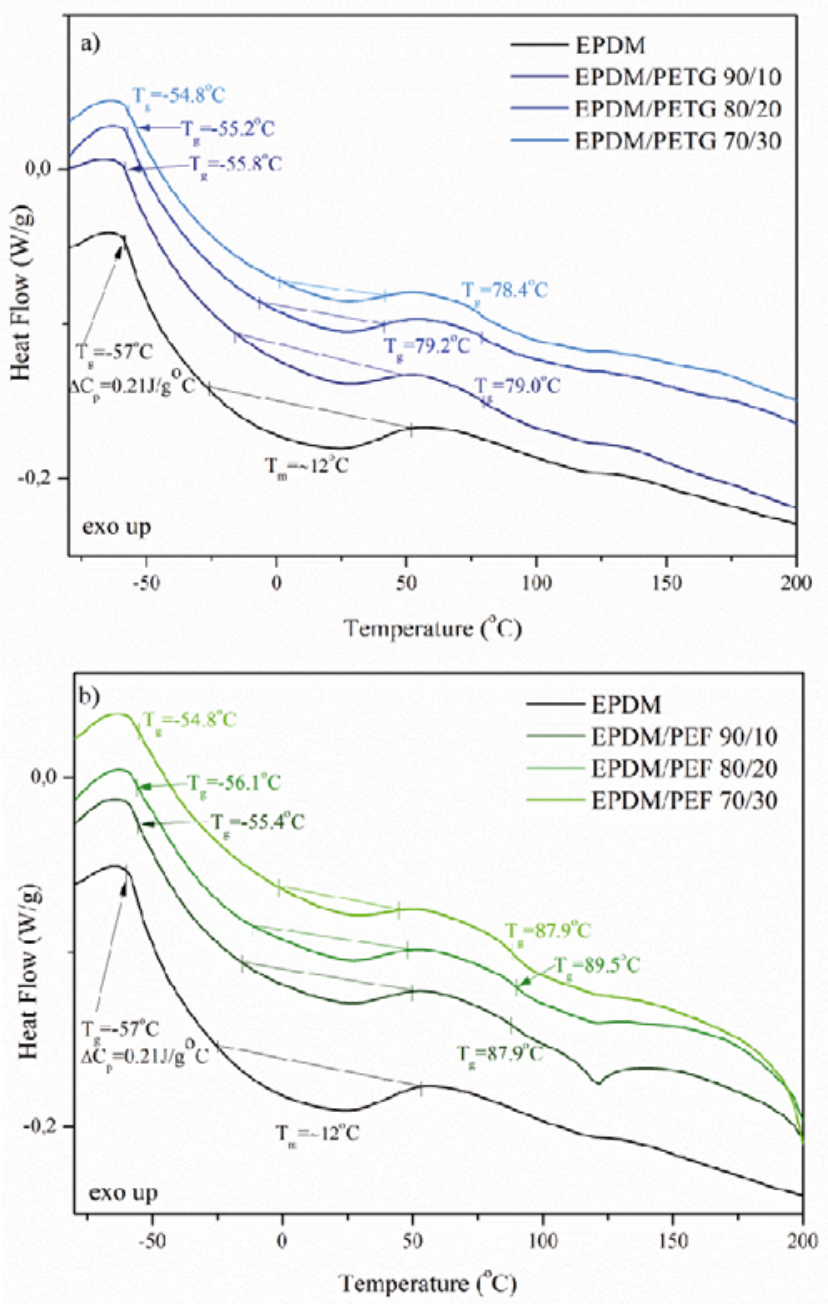

Figure 3. DSC thermograms recorded during 2ng heating for a) EPDM/PETG blends and b) EPDM/PEF blends the crystallites formed on cooling are only very small. The addition of both, PETG or PEF into EPDM affect the glass transition of EPDM phase only in the small manner (decrease of about $1-3^{\circ} \mathrm{C}$ ). Moreover, since both systems were immiscible, one can observe second transition, that comes from the amorphous polyester phase (at about $79^{\circ} \mathrm{C}$ (Fig. 3a) for PETG and at about $88-89^{\circ} \mathrm{C}$ for PEF (Fig. 3b)). Additionally, an increase of amorphous polyester phase content in the system cause a diminution of the melting peak area of EPDM. EPDM is a copolymer in which the ethylene sequences crystallize. If the length of the sequences is relatively large, large crystallites are formed that have a higher melting temperature ${ }^{8}$. With shorter average sequence lengths only very small crystallites are formed that melt immediately above the glass transition temperature. If the sequences consist of only a few $\mathrm{CH}_{2}$ groups, then crystallization is no longer possible and the sample remains amorphous. Thus, the size of EPDM melting peak was affected by the addition of both PETG and PEF amorphous polyesters, which affected the molecular mobility in the amorphous regions $^{34}$ (slight decrease of $T_{g}$ of EPDM).

\section{Tensile properties}

The mechanical properties of EPDM/PETG and EPDM/PEF blends are represented in Fig. 4 and the characteristic parameters (stress at strain of $100 \%$, yield stress and strain, stress and strain at break) are summarized in Table 2. Moreover the values of hardness and hydrostatic density were measured for two series of blends and presented in Table 2. The values of stress at strain of $100 \%$ initially decrease, when the amount of amorphous polyester phase increase from 10 to $20 \mathrm{wt}$. $\%$ and subsequently increase for the blends with the highest content of $30 \mathrm{wt} . \%$. Such trend was visible for systems of EPDM/PETG and EPDM/PEF. This might result from the inhomogeneity in the systems. Moreover, for three systems, i.e. EPDM/PETG 70/30, EPDM/PEF 80/20 and EPDM/PEF 70/30 the values of yield stress and corresponding yield strain were presented in Table 2. In the case of EPDM/PEF blends, these values were within the limit of the measurement error. Moreover, along with an increase in the second component content, the 
Table 2. Physical properties of EPDM-based polymer blends

\begin{tabular}{|l|c|c|c|c|c|c|c|}
\hline Sample & $\begin{array}{c}\sigma_{100 \%} \\
{[\mathrm{MPa}]}\end{array}$ & $\begin{array}{c}\sigma_{\mathrm{y}} \\
{[\mathrm{MPa}]}\end{array}$ & $\begin{array}{c}\varepsilon_{\mathrm{y}} \\
{[\%]}\end{array}$ & $\begin{array}{c}\sigma_{\mathrm{b}} \\
{[\mathrm{MPa}]}\end{array}$ & $\begin{array}{c}\varepsilon_{\mathrm{b}} \\
{[\%]}\end{array}$ & $\begin{array}{c}\mathrm{H} \\
{\left[\mathrm{Sh}^{\circ} \mathrm{A}\right]}\end{array}$ & $\begin{array}{c}\mathrm{d} \\
{\left[\mathrm{g} / \mathrm{cm}^{3}\right]}\end{array}$ \\
\hline EPDM/PETG 90/10 & $0.71 \pm 0.03$ & - & - & $2.11 \pm 0.19$ & $987.90 \pm 94.18$ & $41 \pm 1$ & $0.99 \pm 0.01$ \\
\hline EPDM/PETG 80/20 & $0.60 \pm 0.01$ & - & - & $1.88 \pm 0.18$ & $1266.36 \pm 153.01$ & $46 \pm 2$ & $1.00 \pm 0.01$ \\
\hline EPDM/PETG 70/30 & $0.90 \pm 0.11$ & $0.91 \pm 0.08$ & $41.74 \pm 2.65$ & $1.31 \pm 0.12$ & $737.54 \pm 83.17$ & $60 \pm 2$ & $1.01 \pm 0.01$ \\
\hline EPDM/PEF 90/10 & $0.76 \pm 0.05$ & - & & $1.69 \pm 0.16$ & $951.97 \pm 117.47$ & $48 \pm 1$ & $1.01 \pm 0.01$ \\
\hline EPDM/PEF 80/20 & $0.70 \pm 0.04$ & $0.72 \pm 0.03$ & $45.78 \pm 3.91$ & $1.14 \pm 0.05$ & $754.40 \pm 74.65$ & $52 \pm 1$ & $1.03 \pm 0.01$ \\
\hline EPDM/PEF 70/30 & $0.66 \pm 0.04$ & $0.73 \pm 0.05$ & $37.26 \pm 1.94$ & $0.75 \pm 0.05$ & $646.28 \pm 67.02$ & $63 \pm 2$ & $1.08 \pm 0.01$ \\
\hline
\end{tabular}

$\sigma_{(100 \%)}$ - stress at strain of $100 \% ; \sigma_{y}, \varepsilon_{y}-$ yield stress and strain respectively, $\sigma_{b}, \varepsilon_{b}-$ stress and strain at break respectively; $H$ - hardness; $d-$ density

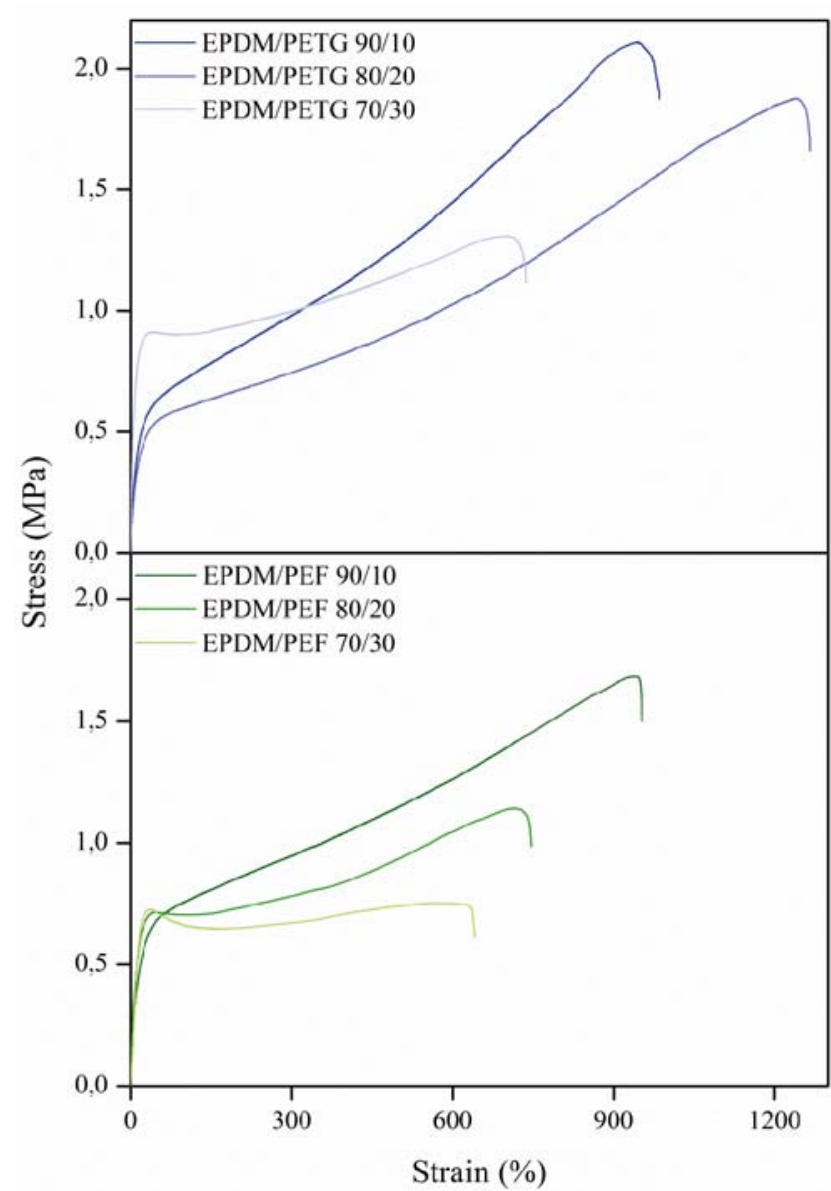

Figure 4. Representative stress-strain curves for two series of polymer blends: EPDM/PETG (above) and EPDM/ PEF (below)

values of stress at break decreased of about $40 \%$ for EPDM/PETG 70/30 and of about $55 \%$ for EPDM/PEF $70 / 30$ if compared to the blend with the lowest content of polyester phase $(10 \mathrm{wt} . \%)$. In the context of blend compatibility, $\varepsilon_{\mathrm{b}}$ is a very sensitive indicator of component adhesion, for mechanically compatible systems, or cohesion, for miscible blends ${ }^{43}$. In this case, for EPDM/ PETG system the value of $\varepsilon_{\mathrm{b}}$ firstly increased and then decreased, while for EPDM/PEF system, along with an increase of PEF content the value of $\varepsilon_{\mathrm{b}}$ decreased. Since the SEM micrographs (Fig. 2) showed non compatible EPDM and PETG or PEF phases, which lead to cracks and fracture at interphase boundaries ${ }^{41}$, also tensile tests revealed both systems were immiscible. However, at the same time, the values of Shore hardness increased of about $50 \%$ for EPDM/PETG blends and $30 \%$ for EPDM/PEF blends. Such improvement might result from the decrease in molecular mobility (Fig. 3). Moreover, the increasing content of the second component in the
EPDM-based blends caused an increase in the values of density. These values of density of blends are between the values of neat EPDM (about $0.86 \mathrm{~g} / \mathrm{cm}^{344}$ ) and PETG $\left(\sim 1.24 \mathrm{~g} / \mathrm{cm}^{3}[45]\right)$ or PEF $\left(\sim 1.43 \mathrm{~g} / \mathrm{cm}^{346}\right)$.

\section{Thermo-oxidative analysis}

The thermo-oxidative stability of both systems of EPDM/PETG and EPDM/PEF blends was studied under oxidative atmosphere. The mass loss (TG) and derivative of mass loss (DTG) curves, with different contents of amorphous polyesters phase, are shown in Fig. 5. Moreover, the characteristic temperatures of 5 $\left(\mathrm{T}_{5 \%}\right), 10\left(\mathrm{~T}_{10 \%}\right), 50\left(\mathrm{~T}_{50 \%}\right)$ and $90\left(\mathrm{~T}_{90 \%}\right) \%$ of mass loss in oxidative atmosphere are summarized in Table 3. One can consider the value of $\mathrm{T}_{5 \%}$ as the beginning of thermal degradation. The EPDM/PETG blends exhibit two steps of the degradation under oxidative atmosphere. In step 1, the volatile compounds and water are evolved from the samples. For this series of blends the midpoint temperatures are about $290^{\circ} \mathrm{C}$ and the step height is between $5-10 \%$. Step 2 has to do mainly with
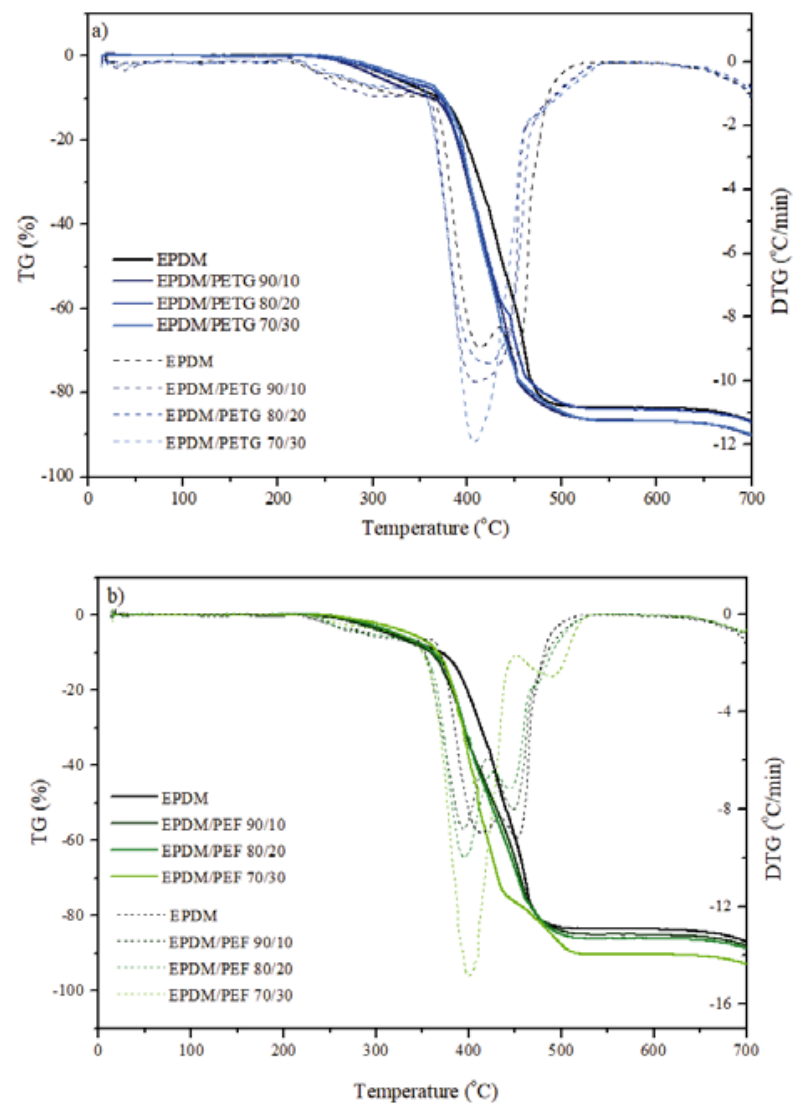

Figure 5. The mass loss and derivative of mass loss as a function of temperature for a) EPDM/PETG blends and b) EPDM/PEF blends 
Table 3. Thermo-oxidative stability parameters of EPDM-based polymer blends

\begin{tabular}{|l|c|c|c|c|}
\hline \multicolumn{1}{|c|}{ Sample } & $\begin{array}{c}\mathrm{T}_{5 \%} \\
{\left[{ }^{\circ} \mathrm{C}\right]}\end{array}$ & $\begin{array}{c}\mathrm{T}_{10 \%} \\
{\left[{ }^{\circ} \mathrm{C}\right]}\end{array}$ & $\begin{array}{c}\mathrm{T}_{50 \%} \\
{\left[{ }^{\circ} \mathrm{C}\right]}\end{array}$ & $\begin{array}{c}\mathrm{T}_{90 \%} \\
{\left[{ }^{\circ} \mathrm{C}\right]}\end{array}$ \\
\hline EPDM & 321 & 371 & 438 & - \\
\hline EPDM/PETG 90/10 & 305 & 362 & 423 & 696 \\
\hline EPDM/PETG 80/20 & 323 & 372 & 425 & - \\
\hline EPDM/PETG 70/30 & 335 & 375 & 422 & 699 \\
\hline EPDM/PEF 90/10 & 314 & 360 & 427 & - \\
\hline EPDM/PEF 80/20 & 323 & 362 & 423 & - \\
\hline EPDM/PEF 70/30 & 338 & 367 & 410 & 517 \\
\hline
\end{tabular}

$\mathrm{T}_{5 \%}, T_{10 \%}, T_{50 \%}, T_{90 \%}-$ temperatures corresponding to $5,10,50$ and $90 \%$ of mass loss, respectively

the pyrolysis of PEF and PETG. The peak maximum of the DTG curve is at about. $407-412^{\circ} \mathrm{C}$. In turn, the series of EPDM/PEF blends exhibit three steps of degradation, which is probably due to higher degree of incompatibility (Table 2). The first step is similar, but the second step is divided into two: pyrolysis of EPDM (step 2 at about $390^{\circ} \mathrm{C}$ ) and the pyrolysis of the more stable polymer component (step 3 at the temperature of about $450^{\circ} \mathrm{C}$ ). It is also worth noticing, that the value of $\mathrm{T}_{5 \%}$, which is considered to represent the beginning of thermal degradation, was strongly improved by the addition of both PETG and PEF into EPDM systems and fore mostly this value increased along with increasing content of more stable polymer.

\section{CONCLUSIONS}

In the present work, for the first time, the blends of EPDM with PETG or PEF were prepared and characterized in detail. SEM micrographs along with DSC analysis of EPDM/PETG and EPDM/PEF blends revealed phase separated morphology of the blends. Finer morphology was observed for EPDM/PETG systems, which was in the agreement with the Hoy's method calculations. The addition of PETG caused the improvement in stress at strain of $100 \%$, however at the same time the decrease in stress at break was observed along with an increase of PETG or PEF content in the blends. Moreover, the highest value of elongation at break was reported for EPDM/PETG 80/20. The incorporation of rigid amorphous polyesters caused a strong improvement in hardness. Moreover, the temperature of the beginning of thermo-oxidative degradation $\left(\mathrm{T}_{5 \%}\right)$ was shifted toward higher values when PETG or PEF were incorporated into EPDM. Based on the above results one can draw the conclusion that PETG is more promising polyester, that can improve the properties of rubber-based blends.

\section{Acknowledgments}

This work is the result of the research project INNOTECH-K3/IN3/53/228403/NCBR/14 funded by the National Center for Research and Development.

\section{LITERATURE CITED}

1. Zhang, H., Datta, R.N., Talma, A.G. \& Noordermeer, J.W.M. (2010). Modification of EPDM with alkyphenol polysulfide for use in tire sidewalls, 1-mechanical properties. $M a$ cromol. Mater. Eng. 295, 67-75. DOI:10.1002/mame.200900126.

2. Stelescu, M.D., Airinei, A., Grigoras, C. \& Niculescu-Aron I.G. (2010). Use of Differential Scanning Calorimetry
(DSC) in the Characterization of EPDM/PP blends. Int. J. Thermophys. 31, 2264-2274. DOI: 10.1107/s10765-010-0872-z.

3. Waddell, W.H. (1998). Tire Black Sidewall Surface Discoloration and Non-Staining Technology: A Review. Rubb. Chem. Technol. 71(3), 590-618. DOI: 10.5254/1.3538493.

4. Ivan, G. (1993). Dynamic vulcanization an accesible way to thermoplastic elastomers. Iran. J. Polym. Sci. Technol. 2(1), 3-11.

5. Shonaike, G.O. \& Simon, G.P. (1993). Polymer Blends and Alloys. New York, USA: Marcel Dekker Inc.

6. Utracki, L.A. \& Favis, B.D. (1989). Handbook of Polymer Science and Technology. In Cheremisinoff, N.P. (Ed.), Polymer alloys and blends (Chapter 4). New York and Basel: Mercel Dekker, Inc.

7. Paul, D.R. \& Newman S. (Eds.) (1972). Polymer blends, New York, USA: Academic Press

8. Walker, B.M. (Ed.) (1979). Handbook of Thermoplastic Elastomers, New York, USA: Van Nostrand Reinhold

9. De, S.K. \& Bhowmick, A.K. (Eds.) (1990). Thermoplastic Elastomers from Rubber Plastic Blends, New York, USA: Ellis \& Horwood

10. Wu, S. (1985). Phase structure and adhesion in polymer blends: A criterion for rubber toughening. Polymer 26(12), 1855-1863. DOI: 10.1016/0032-3861(85)90015-1.

11. Coran, A.Y., Patel, R.P. \& Williams, D. (1982). RubberThermoplastic Compositions. Part V. Selecting Polymers for Thermoplastic Vulcanizates, Rubb. Chem. Technol. 54, 116-136. DOI:10.5254/1.3535861.

12. Park, J.G., Kim, D.H. \& Suh, K.D. (2000). Blends of Polyethyleneterephthalate with EPDM through Reactive Mixing, J. Appl. Polym. Sci. 78(12), 2227-2233. DOI: $10.1002 / 1097-4628(20001213) 78: 12<2227:: A I D-A P-$ P210>3.0.CO;2-0.

13. Turner, S.R. (2004). Development of amorphous copolyesters based on 1,4-cyclohexanedimethanol, J. Polym. Sci. Part A: Polym. Chem. 42(23), 5847-5842. DOI: 10.1002/pola.2046.

14. Tsai, Y., Fan, C.H., Hung, C.Y. \& Tsai, F.J. (2011). Transparent Copolyester/Organoclay Nanocomposites Prepared by In Situ Intercalation Polymerization: Synthesis, Characterization, and Properties, Polym. Compos. 32(1), 89-96. DOI: 10.1002/pc.21021.

15. Tsai, Y., Fan, C.H., Hung, C.Y. \& Tsai, F.J. (2008). Amorphous copolyesters based on 1,3/1,4-cyclohexanedimethanol: Synthesis, characterization and properties, J. Appl. Polym. Sci. 109(4), 2598-2604. DOI: 10.1002/app.28385.

16. Tsai, Y., Fan, C.H., Hung, C.Y. \& Tsai, F.J. (2007). Poly(ethylene terephthalate) copolymers that contain 5-tertbutylisophthalic acid and 1-3/1-4-cyclohexanedimethanol: Synthesis, characterization, and properties, J. Appl. Polym. Sci. 104(1), 279-285. DOI: 10.1002/app.25592.

17. Villa, A., Schiavoni, M., Campisi, S., Veith, G.M. \& Prati, L. (2013). Pd-modified Au on carbon as an effective and durable catalyst for the direct oxidation of HMF to 2,5-furandicarboxylic acid, Chem. Sus. Chem. 6(4), 609-612. DOI: $10.1002 /$ cssc.201200778.

18. Wang, J., Liu, X., Zhang, Y., Liu, F. \& Zhu, J. (2016). Modification of poly(ethylene 2,5-furandicarboxylate) with 1,4- cyclohexanedimethylene: Influence of composition on mechanical and barrier properties, Polymer 103, 1-8, DOI: 10.1016/j.polymer.2016.09.030.

19. Pillon, L.Z. \& Utracki, L.A. (1984). Compatibilization of polyester/polyamide blends via catalytic ester-amide interchange reaction, Polym. Eng. Sci. 24(17), 1300-1305. DOI: 10.1002/ pen.760241706.

20. Pillon, L.Z., Utracki, L.A. \& Pillon, D.W. (1987). Spectroscopic study of poly(ethylene terephthalate)/poly(amide-6,6) blends, Polym. Eng. Sci. 27(8), 562-567. DOI: 10.1002/ pen.760270806.

21. Subramanian, P.M. (1987). Poly(ethylene terephthalate) blends for permeability barrier applications, Polym. Eng. Sci. 27(21), 1574-1581. DOI: 10.1002/pen.760272103. 
22. Hourston, D.J., \& Lane, S. (1994). Toughened polyesters and polycarbonates. In: Collyer A.A. (eds) Rubber Toughened Engineering Plastics. Springer, Dordrecht.

23. Hourston, D.J., Koetsier, D.W., Lane, S. \& Zhang, H.X. (1990). In 33rd IUPAC International Symposium On Macromolecules, 8-13 July 1990, Montreal, Canada.

24. Droescher, M., Gerth, C. \& Bornschlegl, E. (1986). German Patent No. 3,510,409. Germany: German Patent and Trade Mark Office.

25. Aravind, I., Albert, P., Ranganathaiah, C., Kurian, V. \& Thomas, S. (2004). Compatibilizing effect of EPM-g-MA in $\mathrm{EPDM} /$ poly(trimethylene terephthalate) incompatible blends, Polymer 45(14), 4925-4937. DOI: 10.1016/j.polymer.2004.04.063.

26. Wang, X.H., Zhang, H.Z., Wang, Z.G. \& Jiang, B.Z. (1997). Toughening of poly(butylene terephthalate) with epoxidized ethylene propylene diene rubber, Polymer 38(7), 1569-1572. DOI: 10.1016/S0032-3861(96)00674-X.

27. Grigoryeva, O.P. \& Karger-Kocsic, J. (2000). Melt grafting of maleic anhydride onto an ethylene-propylene-diene terpolymer (EPDM), Europ. Polym. J. 36(7), 1419-1429. DOI:10.1016/ S0014-3057(99)00205-0.

28. Khosrokhavar, R., Naderi, G., Bakhshandeh, G.R. \& Ghoreishy, M.H.R. (2011). Effect of processing proerties on PP/EPDM/organoclay nanocomposites using Taguchi analysis method, Iran. Polym. J. 20(1), 41-53.

29. Paszkiewicz, S., Szymczyk, A., Špitalský, Z., Mosnáček, J., Janus, E. \& Rosłaniec, Z. (2013), Effect of Addition of Expanded Graphite (EG) on the Synthesis and Characteristics of Poly(ethylene terephthalate) Modified with Cyclohexanedimethanol, Polimery (Warsaw) 58(11-12), 47-53. DOI: 10.14314/ polimery.2013.893.

30. Kwiatkowska, M., Kowalczyk, I., Kwiatkowski, K., Szymczyk, A. \& Roslaniec Z. (2016). Fully biobased multiblock copolymers of furan-aromatic polyester and dimerized fatty acid: Synthesis and characterization, Polymer 99(2), 503-512. DOI: 10.1016/j.polymer.2016.07.060.

31. Van Krevelen, D.W. \& Te Nijenhuis, K. (2009). Properties of Polymers (4th ed.) (pp. 201-222). Amsterdam, Netherlands: Elsevier B.V.

32. Hoy, K.L. (1970). New values of the solubility parameters from vapor pressure data, J. Paint. Technol. 42(541), 76-118.

33. Koenhen, D.M. \& Smolders, C.A. (1975). The determination of solubility parameters of solvents and polymers by means of correlations with other physical quantities, J. Appl. Polym. Sci. 19(4), 1163-1179. DOI: 10.1002/app.1975.070190423.

34. Holden, G., Legge, N.R., Quirk, R.P. \& Schroeder, H. E. (1996). Thermoplastic Elastomers (2nd ed.). Munich, Germany: Hanser Publishers.

35. Fakirov, S. (2005). Handbook of Condensation Thermoplastic Elastomers. Weinheim, Germany: Wiley-VCH.

36. Callan, J.E., Hess, W.M. \& Scott, C.E. (1971). Elastomer Blends. Compatibility and Relative Response to Fillers. Rubb. Chem. Technol. 44(3), 814-837. DOI: 10.5254/1.3544796.

37. Nielsen, L.E. (1974). Morphology and the elastic modulus of block polymers and polyblends. Rheol. Acta 13(1), 86-92. DOI: $10.1007 / \mathrm{BF} 01526889$.

38. Danesi, S. \& Porter, R.S. (1978). Blends of isotactic polypropylene and ethylene-propylene rubbers: rheology, morphology and mechanics, Polymer 19, 448-457. DOI: 10.1016/00323861(78)90255-0.

39. Paul, D.R. \& Barlow, J.W. (1980). Polymer Blends, J. Macromol. Sci. Part C Polym. Rev. C18(1), 109-168. DOI: 10.1080/00222358008080917.

40. Elmendrop, J.J. \& Maalcke, R.J. (1985). A study on polymer blending microrheology: Part 1, Polym. Eng. Sci. 25(16), 1041-1047. DOI: 10.1002/pen.760251608.

41. Jose, S., Aprem, A.S., Francis, B., Chandy, M.C., Werner, P., Alsteadt, V. \& Thomas, S. (2004). Phase morphology, crystallisation behaviour and mechanical properties of isotactic polypropylene/high density polyethylene blends, Europ. Polym. J. 40(9), 2105-2115. DOI: 10.1016/j.eurpolymj.2004.02.026.

42. Plochocki, A.P., Dagli, S.S. \& Andrews, R.D. (1990).

The interface in binary mixtures of polymers containing a corresponding block copolymer: Effects of industrial mixing processes and of coalescence, Polym. Eng. Sci. 30(12), 741-752. DOI: 10.1002/pen.760301207.

43. Olabisi, O., Robeson, L.M. \& Shaw, M.T. (1979). Polymer - Polymer Miscibility, New York, USA: Academic Press

44. Piesowicz, E., Irska, I. \& Roslaniec, Z. (2017). EPDM/ EVA thermoplastic vulcanizates (TPV) - effect of vinyl acetate content and oil extension on blend properties, Elastomery 21(2), 82-91.

45. Paszkiewicz, S., Szymczyk, A., Pawlikowska, D., Irska, I., Piesowicz, E., Jotko, M., Lisiecki, S., Bartkowiak, A., Sieradzka M., Fryczkowski, R., Kochmanska, A., Kochmanski, P. \& Roslaniec, Z. (2017). Improvement of barrier properties of glycol modified poly(ethylene terephthalate) based nanocomposites containing graphene derivatives forms, Polimery (Warsaw) 62(11-12), 908-914. DOI: 10.14314/polimery.2017.908.

46. Burgess, S.K., Leisen, J.E., Kraftschik, B.E., Mubarak, C.R., Kriegel, R.M. \& Koros, W.J. (2014). Chain Mobility, Thermal, and Mechanical Properties of Poly(ethylene furanoate) Compared to Poly(ethylene terephthalate), Macromol. 47(4), 1383-1391. DOI: 10.1021/ma5000199. 